\title{
Fellow Column: An Unbalanced Translocation Involving Partial Duplication of Chromosome 6 and Partial Deletion of Chromosome 10 in a Premature Infant with Tetralogy of Fallot
}

Kevin Mo, Teagan Tran, Arjina Boodaghian, John Wear, John Ho, MD, Robin Clark MD, Mitchell Goldstein MD

\section{Abstract}

Purpose: To report a case of simultaneous chromosome 10 partial deletion and chromosome 6 partial duplication in a preterm infant.

Methods: This is a retrospective case report followed with clinical observation, echocardiogram, and genetic testing.

Results: A neonate with Tetralogy of Fallot, clubbed feet, low set ears, and webbed neck was found to have chromosomal abnormalities that are consistent with unbalanced translocation between chromosomes 6 and 10, resulting in a partial duplication of chromosome 6 and partial deletion of chromosome 10.

Discussion: Chromosome microarray testing in a patient with multiple congenital anomalies can facilitate rapid diagnosis and treatment with the potential to improve the management of complications and subsequent development.

\section{Introduction}

Prematurity is commonly associated with respiratory distress syndrome, patent ductus arteriosus, apnea of prematurity, hypoglycemia, and fetal exposure to drugs of abuse. Prematurity is also common in neonates with structural cardiac anomalies, limb abnormalities, and facial dysmorphism. We report a preterm infant

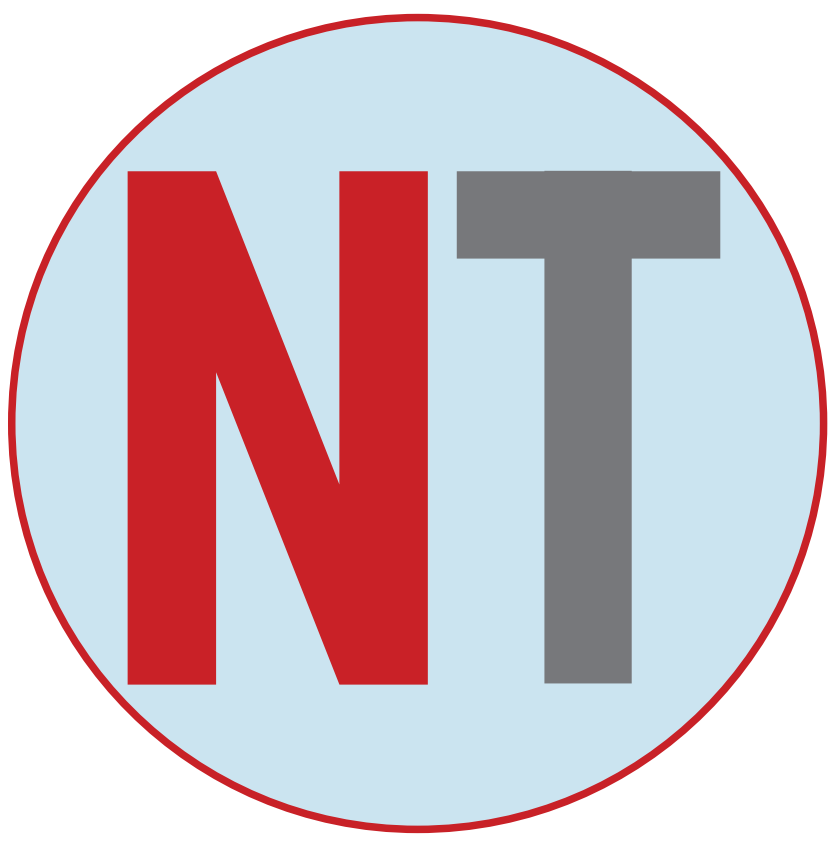

treated in the neonatal intensive care unit with chromosome 6 and 10 abnormalities.

\section{Methods}

A retrospective chart review was performed on a patient who presented to the Emanate Health Queen of the Valley Neonatology Intensive Care Unit (West Covina, CA) following the preterm delivery of a twin gestation. Subsequent growth, developmental, cardiac, and musculoskeletal anomalies were monitored in the NICU.

\section{Case Report}

Baby $\mathrm{M}$ is a 36 week and 1-day gestation infant born to a 20-yearold Hispanic G2P1 woman who is blood type O positive. The mother's first pregnancy led to premature delivery and rapid demise of an infant with multiple congenital abnormalities. In the second pregnancy, dichorionic diamniotic fraternal twins with intrauterine growth restriction (smaller twin B; Baby M) were diagnosed with club feet and congenital heart disease on prenatal ultrasound. There was persistent absent end-diastolic flow in twin B. Due to suspected fetal anomaly and fetal distress; a cesarean section was performed.

\section{"In the second pregnancy, dichorionic diamniotic fraternal twins with intrauterine growth restriction (smaller twin B; Baby M) were diagnosed with club feet and congenital heart disease on prenatal ultrasound. There was persistent absent end-diastolic flow in twin B."}

The mother underwent general anesthesia, and amniotic fluid was clear. The presentation of this patient was breech. The baby had poor respiratory effort and required supplemental $\mathrm{O}_{2}$ with positive pressure ventilation. APGAR scores were 5 and 9 and $1 \mathrm{~min}$

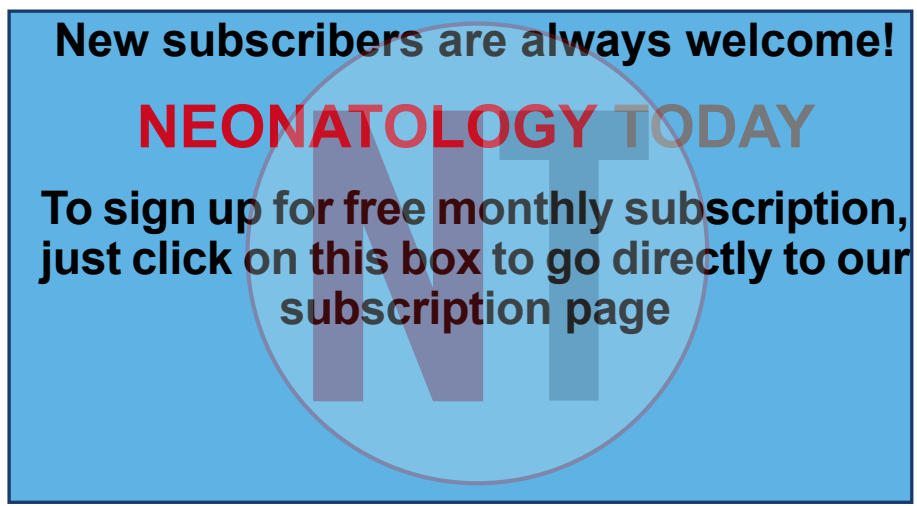


and $5 \mathrm{~min}$, respectively. Following delivery, the mother and the patient's twin were stable and were discharged without any significant complications.

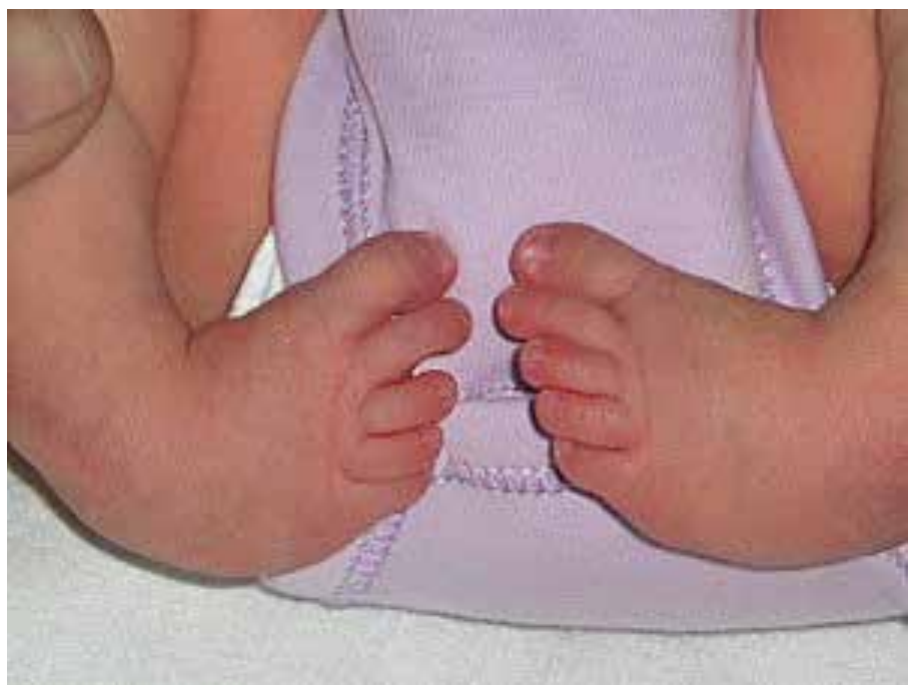

Clubfoot [internet]. Wikipedia [cited Sep 17 2020]. Available from: https://commons.wikimedia.org/wiki/File:Pied bot, varus \%C3\%A9quin (bilateral).jpg.

This 36 weeks gestation female was small for gestational age for all growth parameters: birth weight was $1255 \mathrm{~g}$ (<3\%tile), head circumference was $26.5 \mathrm{~cm}$ ( $<3 \%$ tile), the length was $38 \mathrm{~cm}$ ( $<3 \%$ tile). The temperature was 36.1 , the heart rate was 152 , the respiratory rate was 79 , and the blood pressure was $57 / 25$. The chest had mild to moderate retractions in the substernal and intercostal areas consistent with prematurity. Breath sounds were clear and equal bilaterally. There was a 4/6 systolic murmur throughout the precordium. Other significant features were micrognathia, webbed neck, contracted fingers, club feet, low set ears, and epicanthal folds. The abdomen was soft and flat with normal external genitalia. The baby had bilateral club feet. Her hips were stable. She responded to tactile stimulation with diminished tone and decreased spontaneous activity. The skin was pink and adequately perfused. The infant was managed on non-invasive ventilation. She was placed on NPO on admission and started on IV D10 at $100 \mathrm{ml} / \mathrm{kg} /$ day. The baby had initial hypoglycemia that resolved with IV therapy. The baby advanced to full cycled feeds of PE 24hp. There were no known maternal risk factors for infection. The baby had hyperbilirubinemia of prematurity and received phototherapy. The infant had no unusual movements or seizure-like activity.
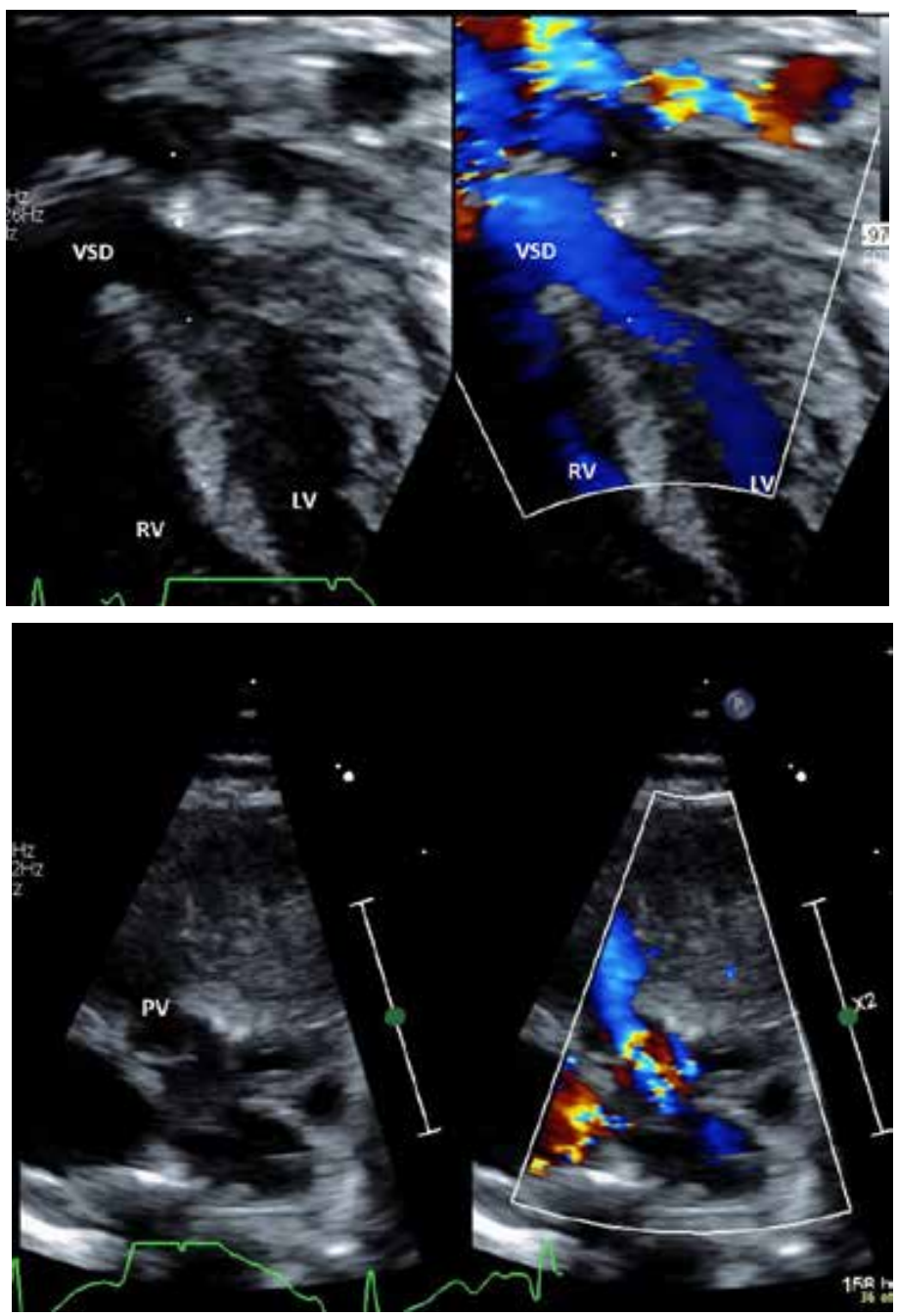

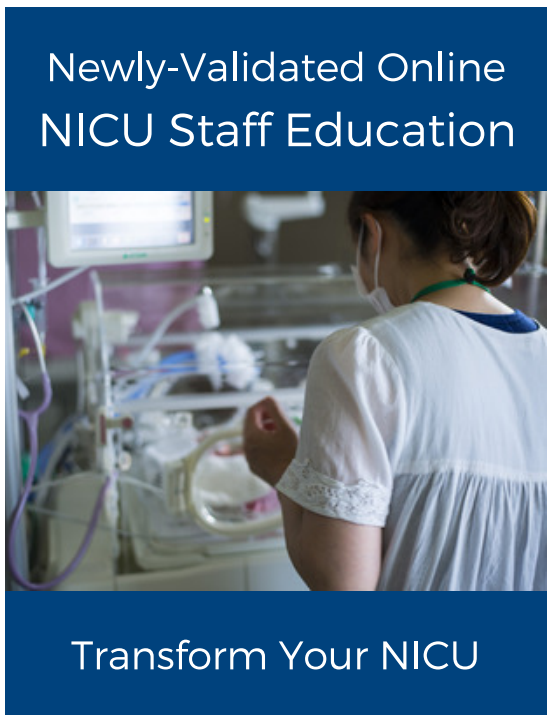

\title{
Caring for Babies and their Families:
} Providing Psychosocial Support to NICU Parents

\author{
based on the "Interdisciplinary Recommendations for Psychosocial \\ Support for NICU Parents."
}

\section{Contact sara@mynicunetwork.com for more information.}

\section{Brought to you by a collaboration between}

- National Perinatal Association

- Patient + Family Care

- Preemie Parent Alliance

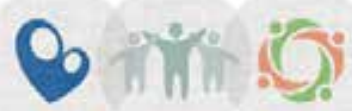




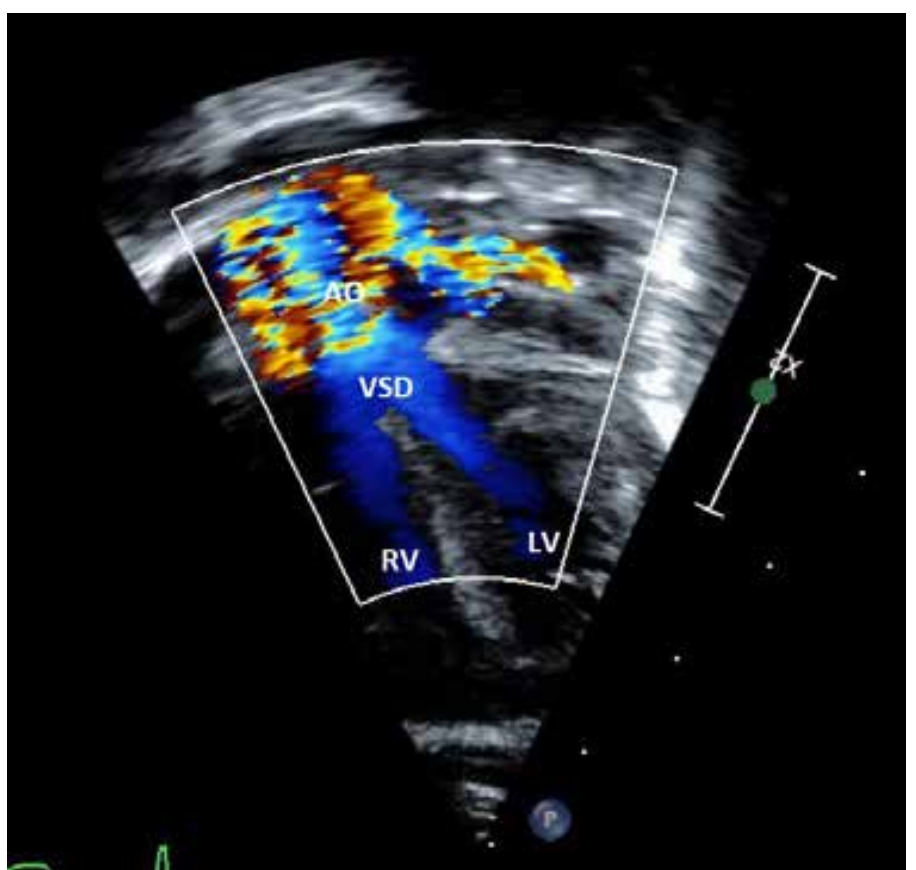

Echocardiogram images courtesy of Dr. John Ho

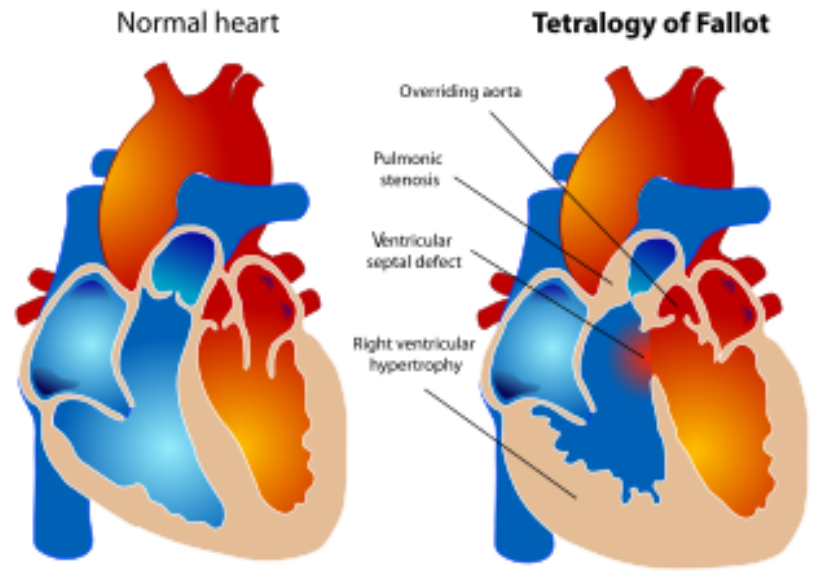

Tetralogy of Fallot [internet]. Wikipedia [cited Sep 17 2020]. Available from: https://commons. wikimedia.org/wiki/File:Tetralogy of Fallot.svg

Echocardiograms on day of life 3 and 19 revealed Tetralogy of Fallot with large outlet VSD and overriding aortic root, PFO, ASD, PDA, aortic stenosis, bicuspid aortic valve, pulmonic stenosis, and thick and doming pulmonic valve. The infant was started on Furosemide at 13 days. She underwent routine chromosome analysis with a "reflex" chromosome microarray. Abdominal ultrasound and retinal exams were within normal limits. Serology negative for HIV, Rubella, and Hepatitis B. When the baby reached $2 \mathrm{~kg}$, she was transferred to a tertiary center for further evaluation and heart surgery.

Initial chromosome analysis (LabCorp) was abnormal with extra material of unknown origin on the short arm of chromosome 10: 46,XX, add(10)(p15.1). SNP chromosome microarray (Lab-
Corp) microarray analysis identified a terminal duplication of chromosome $6 q$ and a terminal deletion of chromosome 10p. Microarray testing found a $28.5 \mathrm{MB}$ duplication on chromosome 6 6q24.1 $\rightarrow$ q27 and a 3.8 MB deletion on chromosome 10 at $10 \mathrm{p} 15.3 \rightarrow \mathrm{p} 15.2$, consistent with an unbalanced translocation. Chromosome 6 duplication involved genes PITRMI and ZMYNDII. The chromosome 10 deletion involved NMBR g. The presence of a terminal gain and terminal loss of different chromosomes in the same analysis suggests that the proband may have inherited a single unbalanced derivative chromosome 10 from a parent with the balanced translocation between the two chromosomes. The lab recommended specific FISH analyses for the parents to investigate possible familial genetic rearrangements.

\section{Discussion}

Parents who have balanced chromosome translocations may be asymptomatic, while their offspring with unbalanced translocations may have complex congenital anomalies. Unbalanced translocations can also lead to infertility, miscarriage, or life-threatening congenital anomalies. Baby M's mother had a previous stillbirth, which raises concerns that this translocation is familial, and the mother may carry a balanced version of the $t(6 ; 10)$ translocation. There have been reported cases of chromosome 6;10 translocations, resulting in miscarriage, suggesting that the stillbirth before baby $M$ may have been a result of an inherited unbalanced translocation. [1]

The twin gestation with Baby $\mathrm{M}$ was dichorionic and diamniotic, suggesting that these were fraternal twins, conceived from different gametes. While baby $M$ had a birth weight of $1255 \mathrm{~g}$, twin $A$ was born at almost twice her birth weight and was discharged without any significant anomalies. Because the mother may have had a balanced translocation, further testing was recommended in her. If a familial translocation can be confirmed in one of the parents, further testing is warranted for the asymptomatic twin A who is also at risk to carry a balanced version of the familial translocation. Understanding the results of the microarray analysis can help explain the features of this patient and can potentially help predict future development.

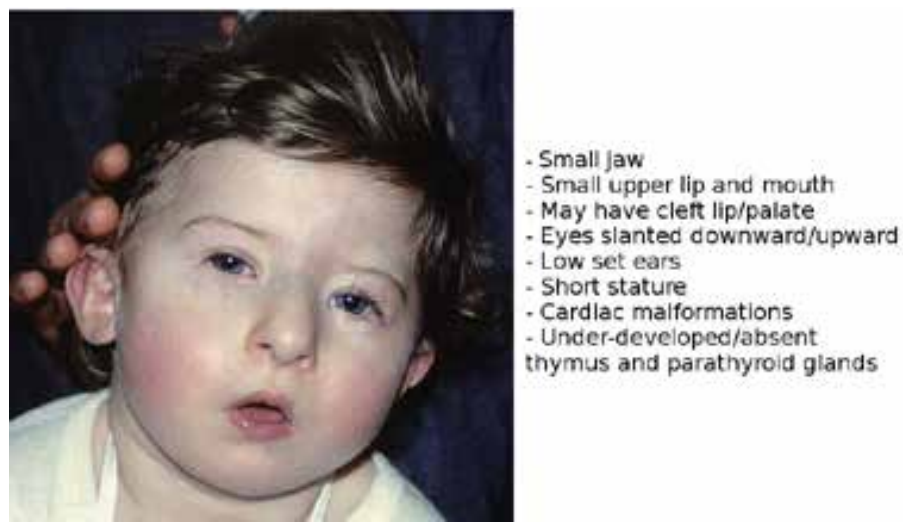

Digeorge Syndrome [internet]. Wikipedia [cited Sep 17 2020]. Available from: https://commons. wikimedia.org/wiki/File:DiGeorge syndrome1.jpg

Deletions in chromosome $10 p$ yield a range of variable symptoms and findings. Associated features include severe intellectual disability, growth delays, short neck, and congenital heart defects. [2] Several cases have also been reported in patients with features 
of DiGeorge syndrome. DiGeorge syndrome, which is a common feature of the $22 q 11.2$ deletion syndrome, presents with the triad of conotruncal heart defects, hypocalcemia, and absent thymus. While the genetic origins of this patient's condition are distinct from DiGeorge syndrome, cardiac anomalies, epicanthal folds, short necks, and widely spaced nipples are similar and point to possible common pathophysiology. Absent thymus, absent parathyroid glands, and possible hypocalcemia in other patients with similar genetic abnormalities have been described.

Specifically, this patient's $10 \mathrm{p} 15.3 \rightarrow \mathrm{p} 15.2$ deletion includes the genes PITRM1 and ZMYND11. PITRM1 codes for an ATP-dependent metalloprotease that degrades post-cleavage mitochondrial transit peptides. [4] The protein binds zinc and can also degrade amyloid beta A4 protein, which suggests a possible link to Alzheimer's disease. ZMYND11 codes for a zinc finger protein that localizes to the nucleus and functions as a transcriptional repressor. [5] Specifically, it is known to bind the adenovirus E1A protein. Deletion of these genes, causing haploinsufficiency for the gene products, could contribute to manifestations related to Alzheimer's and Adenovirus infection in this patient.
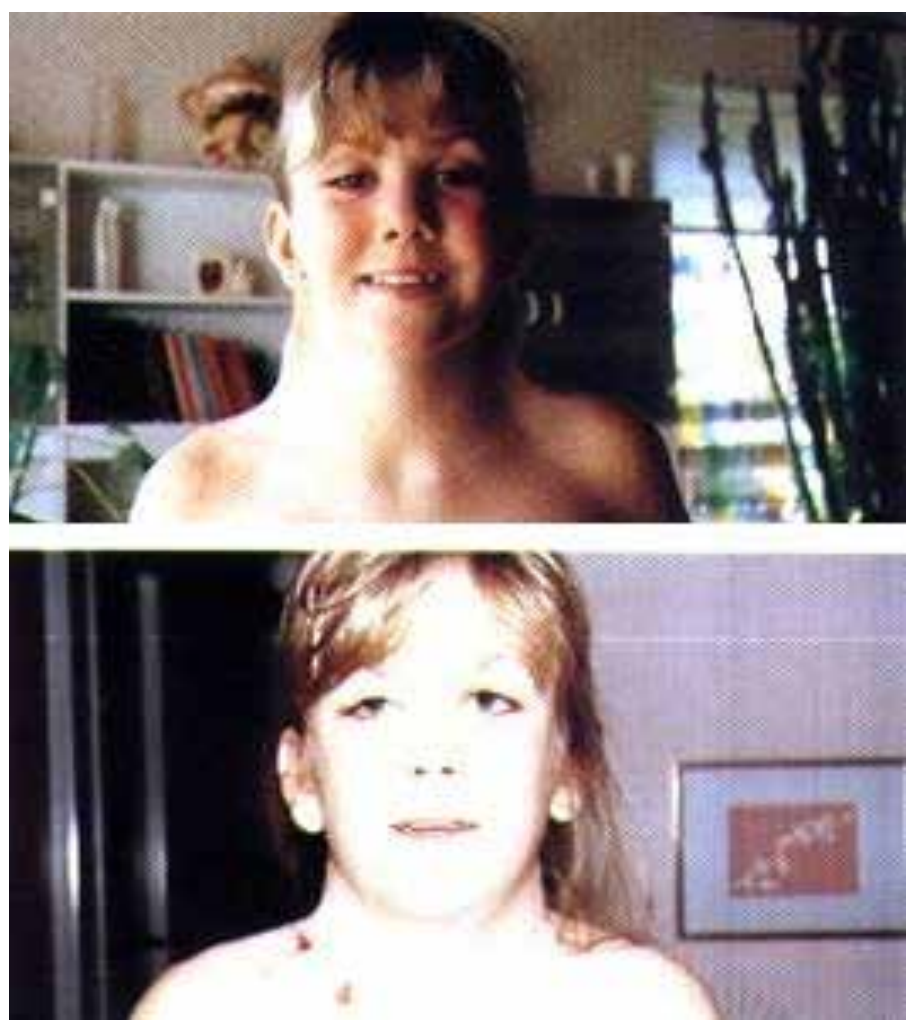

Turner Syndrome [internet]. Wikipedia [cited Sep 17 2020]. Available from: https://commons.wikimedia.org/wiki/File:Neck of girl with Turner Syndrome (before and after).jpg

Duplications in chromosome $6 q$ are extremely rare and can present with growth retardation, mental retardation, webbed neck, musculoskeletal abnormalities, clubbed feet and hands, widespaced nipples, scoliosis, and internal organ manifestations. [3] This patient has features that are consistent with the phenotype associated with chromosome $6 q$ duplication, including the webbed neck, clubbed feet, and wide nipples. The specific $6 q 24.1 \rightarrow$ q27 duplication involves NMBR. This gene encodes for a 7-trans- membrane $G$ protein-coupled receptor that binds neuromedin $B$, a growth factor, and mitogen for gastrointestinal epithelial tissue and normal or neoplastic lungs. [6] This receptor plays a role in smooth muscle contraction, neuronal responses, and cell growth regulation. This gene may also be associated with schizophrenia. Taken together, this patient's chromosome 6 abnormalities may increase the risk for neurodevelopmental problems such as intellectual disability and schizophrenia.

\section{Conclusion}

In this report, we describe a patient with an unbalanced translocation that is likely to be familial. The chromosome $6 q 624.1 \rightarrow q 27$ duplication and chromosome $1010 \mathrm{p} 15.3 \rightarrow \mathrm{p} 15.2$ deletion increase risk for a variety of anomalies that include abnormalities of the thymus, parathyroid glands, and calcium levels. Monitoring for scoliosis and schizophrenia could be warranted later in life. Furthermore, in neonates presenting with signs of Down syndrome or DiGeorge syndrome, evaluation for an unbalanced translocation with chromosome microarray may be warranted. Taken together, this has potential implications for the course of treatment and preparing the patient and parents for complications that may arise in the future.

\section{References}

1) Yang $X$, Zhang $H$, Yu Y, Zhu H, Hu X, Jiang $Y$, Wang $R$, Liu R. Clinical Features of Chromosome 6 Translocation in Male Carriers: A Report of 10 Cases and Review of the Literature. Med Sci Monit. 2018 Jun 18;24:4162-4168. doi: 10.12659/MSM.911170. PMID: 29911662; PMCID: PMC6038718.

2) Martin C, Williams E. Chromosome 10 Monosomy 10p [internet]. NORD: National Organization for Rare Disorders [cited 2020 Aug 11]. Available from: https://rarediseases. org/rare-diseases/chromosome-10-monosomy-10p/

3) Shashikant K. Chromosome 6 Partial Trisomy $6 q$ [internet]. NORD: National Organization for Rare Disorders [cited 2020 Aug 11]. Available from: https://rarediseases.org/rarediseases/chromosome-6-partial-trisomy-6ql

4) PITRM1 Gene [internet]. Genecards: The Human Gene Database [cited 2020 Aug 11]. Available from: https://www. genecards.org/cgi-bin/carddisp.pl?gene=PITRM1

5) ZMYND11 Gene [internet]. Genecards: The Human Gene Database [cited 2020 Aug 11]. Available from: https://www. genecards.org/cgi-bin/carddisp.pl?gene=PITRM1

6) NMBR Gene [internet]. Genecards: The Human Gene Database [cited 2020 Aug 11]. Available from: https://www. genecards.org/cgi-bin/carddisp.pl?gene=PITRM1

7) Ganguly B, Kadam V, Kadam N. Clinical Expression of an Inherited Unbalanced Translocation in Chromosome 6. Hindawi Case Reports in Genetics. 2011 Sep 25.

8) Lindstrand A, Malmgren H, Verri A, et al. Molecular and clinical characterization of patients with overlapping 10p deletions. Am J Med Genet Part A 2010; 152A: 1233-1243

9) Van Esch $\mathrm{H}$, et al. The phenotypic spectrum of the 10p deletion syndrome versus the classical DiGeorge syndrome. Genet Couns. 1999;10:59-65.

10) Jones KL. Smith's Recognizable Patterns of Human Malformation. 5th ed. Philadelphia, PA: W.B. Saunders Company; 1997:616-17.

11) Conrad BA, et al. Duplication 6q22->qter: definition of the phenotype. Am J Med Genet. 1998;78:123-26. 

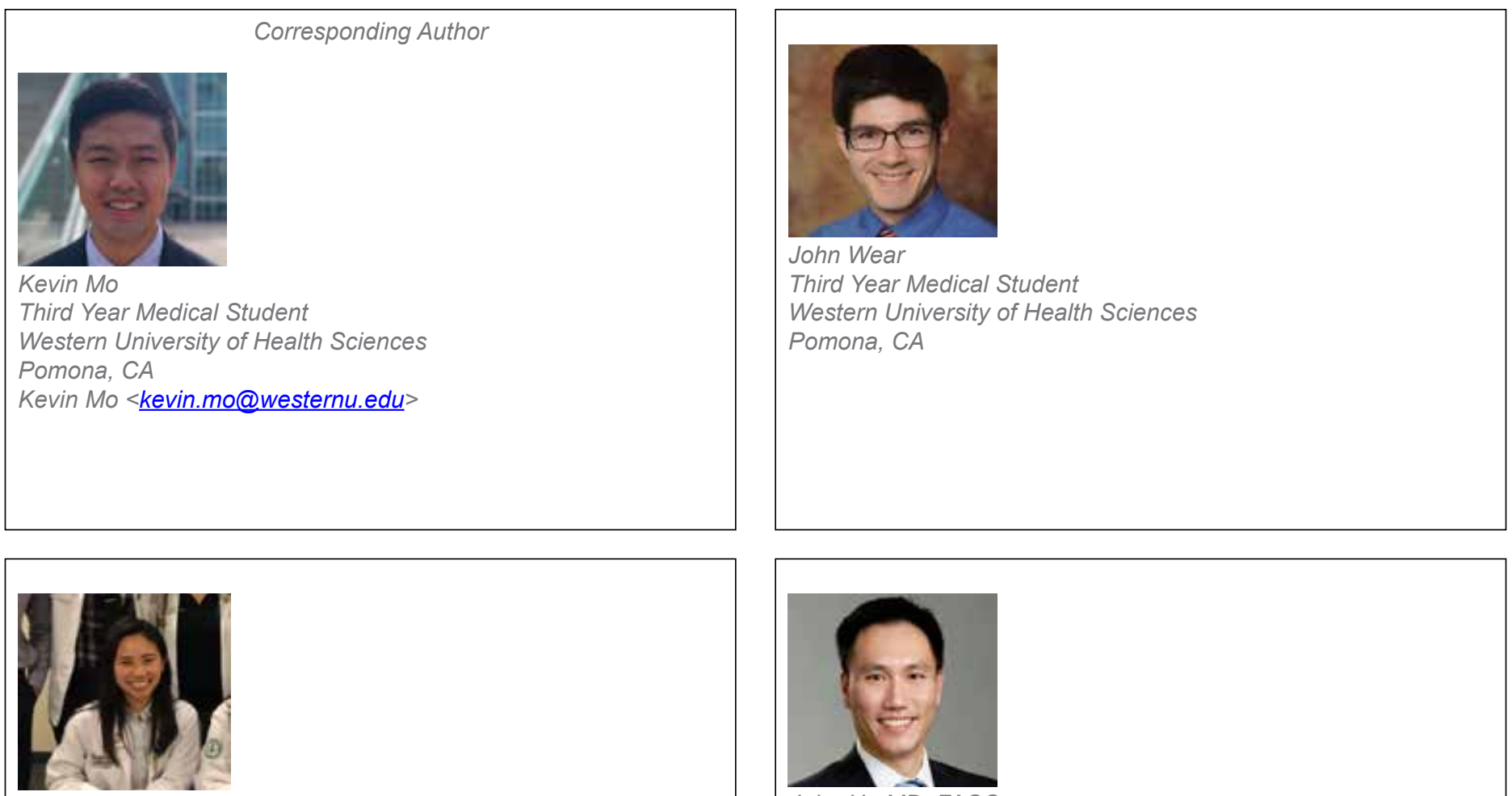

Teagan Tran

Third Year Medical Student

Western University of Health Sciences

Pomona, CA

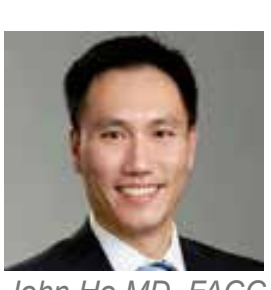

John Ho MD, FACC

Pacific Pediatric Cardiology Medical Group

West Covina, CA
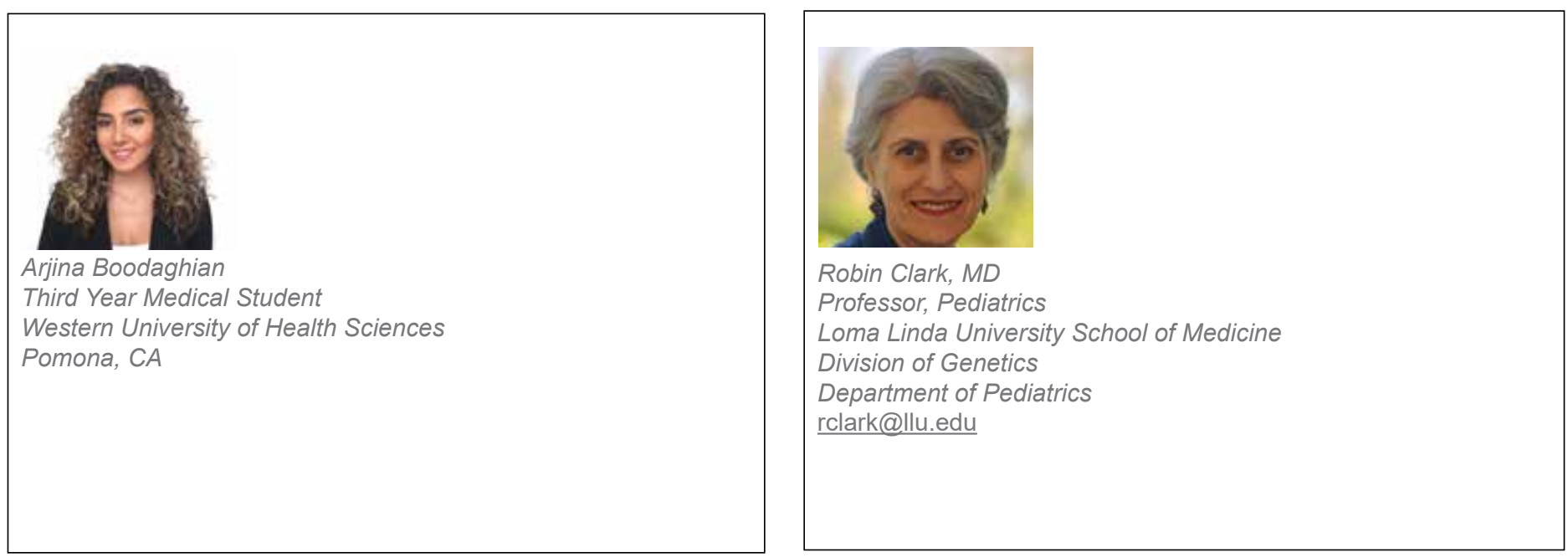


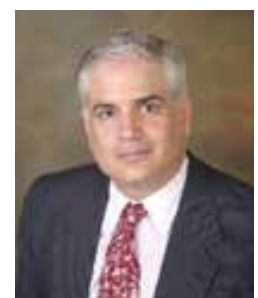

Mitchell Goldstein, MD Professor of Pediatrics

Loma Linda University School of Medicine

Division of Neonatology

Department of Pediatrics

mgoldstein@llu.edu

\section{SAFETY IN THE NICU}

New tubes, new problems?

A new tubing design meant to eliminate tubing misconnections has introduced new challenges for the NICU population. Pediatric providers must deliver medication in small volumes to tiny patients with high levels of accuracy. The new tubing design, known as ENFit ${ }^{\oplus}$, could present dosing accuracy and workflow challenges.

Fellow's Column is published monthly.

- Submission guidelines for "Fellow's Column":

- 2000 word limit not including references or title page. Exceptions will be made on a case by case basis

- QI/QA work, case studies, or a poster from a scientific meeting may be submitted..

- Submission should be from a resident, fellow, or NNP in training.

- Topics may include Perinatology, Neonatology, and Younger Pediatric patients.

- No more than 20 references.

- Please send your submissions to:

Elba Fayard, MD

Interim Fellowship Column Editor LomaLindaPublishingCompany@gmail.com

New subscribers are always welcome! NEONATOLOGY IQDAY

To sign up for a free monthly subscription, just click on this box to go directly to our subscription page

\section{Readers can also follow NEONATOLOGY}

\author{
via our Twitter Feed \\ @NEOTO
}
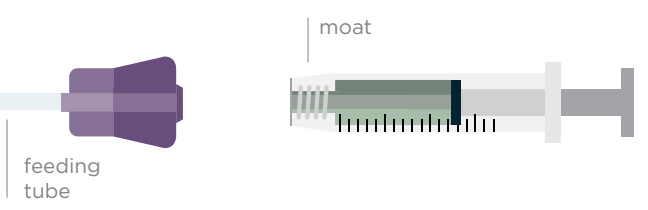

DOSING ACCURACY

- The moat, or area around the syringe barrel, is difficult to clear. Medication can hide there, inadvertently increasing the delivered dose when the syringe and feeding tube are connected; patients may receive extra medication.

\section{INFECTION RISK}

- The moat design can increase risk for infection if residual breast milk or formula remains in the moat and transfers to the feeding tube.

\section{WORKFLOW ISSUES}

- Increased nursing workflow is seen with additional steps for clearing syringe moats, cleaning tube hubs, and using multiple connectors.

Improved standards are important to protect patients from the dangers of tubing misconnections. But we must avoid mitigating existing risks by creating new ones.

Individual hospitals should consider all factors impacting their NICU patients before adopting a new tubing design.

ENFit ${ }^{\oplus}$ is a registered trademark of GEDSA

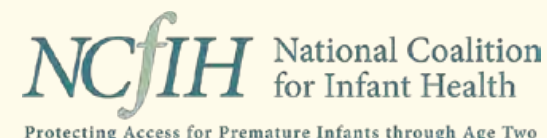

A collaborative of professional, clinical, community health, and family support organizations focused on the health and safety of premature infants.

infanthealth.org 